\title{
Isolation and Some Characteristics of Haemin Dependent Mutants of Bacillus subtilis
}

\author{
By T. J. ANDERSON AND G. IVÁNOVICS \\ Department of Pathology, Glasgow Royal Infirmary, Glasgow
}

(Accepted for publication 5 April 1967)

\begin{abstract}
SUMMARY
Haemin dependent mutants were isolated from Bacillus subtilis after (a) ultraviolet irradiation and selection by streptomycin, $(b)$ exposure of the organisms to copper ions and (c) treatment with $N$-methyl- $N^{\prime}$-nitro- $N$-nitrosoguanidine. The isolates were grown in a synthetic medium containing haemin when substances able to neutralize inhibitory factors and to stabilize the medium were included. Two of the mutants were capable of growth in media supplemented only with $\delta$-aminolaevulinic acid, the first intermediate of porphyrin synthesis. Transformation of the mutants to haemin independence was accomplished using deoxyribonucleic acid.
\end{abstract}

\section{INTRODUCTION}

Genetic recombination in Bacillus subtilis can be effectively studied by means of deoxyribonucleic acid (DNA)-mediated transformation and transduction. These methods have already been used to provide a detailed understanding of the genetic control of drug resistance and of the metabolic pathways leading to the synthesis of amino acids and nucleic acid bases. The present paper describes the isolation of porphyrin auxotrophs of $B$. subtilis. A defined chemical medium for the growth of these auxotrophs has been found and use of this medium has been made in preliminary experiments to investigate genetic recombination between these auxotrophs.

\section{METHODS}

Bacterial strains. The origin and characteristics of each Bacillus subtilis strain used in these experiments are given in Table $\mathrm{I}$.

Phages: SP 50, SP 71, SP91, SP 100 were isolated and described by Földes \& Molnár (1964). The characteristics of phage $3 \mathrm{NT}$ and its method of assay have been previously described by Csiszár \& Ivánovics (1965).

Media. Hartley's meat digest medium (MD) and yeast extract medium (TYE), containing in g./l.: tryptone (Oxoid), 5 ; yeast extract (Oxoid), 3; di-sodium hydrogen orthophosphate (anhydrous), I; at $\mathrm{pH} 7 \cdot 6$, were used for culture under non-defined conditions. Eight per cent ( $\mathrm{v} / \mathrm{v})$ horse blood was added to MD to make blood medium (BM). The chemically defined medium (GGM) of Csiszár \& Ivánovics (I965) was slightly modified and used to establish the essential requirements of strains. The composition was in g./l.: sodium citrate, 3; di-potassium hydrogen orthophosphate, 2; ammonium sulphate, I; L-glutamic acid, 0.2 , magnesium sulphate (hydrated), 0.75 ; ferric ammonium citrate, 0.05 ; glycerol, 15; distilled water to I 1. Glutamic acid was 
converted to its monosodium salt before adding it to the medium. The $\mathrm{pH}$ of the medium was finally adjusted to $7 \cdot 4$. For cultivation of strain RI 2 and all derivative strains the medium was first supplemented with $50 \mu \mathrm{g}$. tryptophan $/ \mathrm{ml}$. Additional supplements were introduced as required from sterile stock solutions immediately prior to use of the medium. Solid media contained $\mathrm{I} \cdot 2 \%$ agar. The minimal medium of Spizizen (1958) was used, with supplements, for transformation experiments.

Table I. Descriptive table of bacterial strains

\begin{tabular}{|c|c|c|c|c|c|c|c|}
\hline \multirow[b]{2}{*}{ Strain } & \multirow[b]{2}{*}{ Source } & \multicolumn{4}{|c|}{ Relevant phenotype } & \multirow[b]{2}{*}{ Genotype* } & \multirow{2}{*}{$\begin{array}{c}\text { Former } \\
\text { designation }\end{array}$} \\
\hline & & Trp & His & Hem & Str & & \\
\hline RI I & a & + & + & + & $\mathbf{S}$ & Prototrophic & Marburg Yale \\
\hline RI 2 & a & - & + & + & $\mathbf{S}$ & $\operatorname{trp}$ & I 68 ind $^{-}$ \\
\hline RI 3 & $b$ & - & - & + & $\tilde{\mathbf{S}}$ & trp, his & SB 25 ind $^{-}$his $^{-}$ \\
\hline RI 4 & $c(R I 2)$ & - & + & + & $\mathbf{R}$ & $\operatorname{trp}$, str-1 & . \\
\hline RI 5 & $c(R I 2)$ & - & + & - & $\mathbf{r}$ & trp, str-2, hem-1 & . \\
\hline RI 6 & $c(\mathrm{RI} 4)$ & - & + & - & $\mathbf{R}$ & trp, str-1, hem-2 & . \\
\hline RI 7 & $\mathrm{C}(\mathrm{RI} 4)$ & - & + & - & $\mathbf{R}$ & trp, str-1, hem-3 & . \\
\hline RI 8 & C (RI 4) & - & + & - & $\mathbf{R}$ & trp, str-1, hem-4 & . \\
\hline RI 9 & $c(R I 4)$ & - & + & - & $\mathbf{R}$ & trp, str-1, hem-5 & . \\
\hline RI IO & $c($ RI 4) & - & + & - & $\mathbf{R}$ & trp, str-1, hem-6 & . \\
\hline RI I I & $c(\mathrm{RI} 4)$ & - & + & - & $\mathbf{R}$ & trp, str-1, hem-7 & . \\
\hline RI $12 \dagger$ & c (RI 3) & - & + & - & $\mathbf{S}$ & trp, hem-3 & . \\
\hline
\end{tabular}

$\operatorname{Trp}=$ tryptophan, His $=$ histidine, Hem $=$ haemin, $\mathrm{Str}=$ streptomycin

*According to the recommendations of Demerec, Adelberg, Clark \& Hartman (1966).

(a) P. Schaeffer, Institute Pasteur, Paris.

(b) S. Zamenhof, University of California, Los Angeles.

(c) This laboratory, with parent strain in parentheses.

tBy transformation with DNA from RI 7 .

$(+)=$ synthesized, $(-)=$ required, $(\mathrm{S})=$ sensitive, $(\mathrm{r})=$ resistant to $50 \mu \mathrm{g} . / \mathrm{ml} .,(\mathrm{R})=$ resistant to $500 \mu \mathrm{g} . / \mathrm{ml}$.

Cultivation techniques. The incubation temperature was $37^{\circ}$ unless stated otherwise. Liquid cultures of bacteria in $10 \mathrm{ml}$. medium in $100 \mathrm{ml}$. Erlenmeyer flasks were aerated in a Gyrotory Shaker (New Brunswick Scient. Co., New Brunswick, U.S.A.) at $260 \mathrm{cyc}$./min. Growth of cultures in flasks with side-arms was followed by measuring optical density of suspensions at $640 \mathrm{~m} \mu$ with a Bausch Lomb Spectronic 20 photometer. Optical density values were then converted either to the number of viable colony forming units, or to dry weight of bacteria per ml. Minimal requirements for cultivation of bacterial strains were first established on supplemented GGM agar and confirmed in liquid media. Anaerobic incubation of bacteria was made in Fildes jars.

Chemicals. Haemin (British Drug Houses Ltd., Poole, England) was prepared as a $0.1 \%(w / v)$ stock solution (Spencer \& Herriot, 1965) under aseptic conditions and stored in the refrigerator at $4^{\circ}$. A solution of Protoporphyrin IX (B grade, Calbiochem Ltd., Los Angeles, U.S.A.) was made in the same way. Solutions of $\delta$-aminolaevulinic acid hydrochloride (ALA) (A grade, Calbiochem Ltd.) dissolved $0.1 \%(w / v)$ in water; cytochrome $c$ (A grade, Calbiochem Ltd.) dissolved $0.1 \%(w / v)$ in physiological saline; catalase (British Drug Houses Ltd., I50,000 e.u./ml.) diluted I/IO (v/v) in physiological saline; and bovine albumin fraction V (AFV) (Armour Pharmaceutical Co. Ltd., Eastbourne, England) dissolved $10 \%(\mathrm{w} / \mathrm{v})$ in water, were each sterilized by Seitz filtration. $N$-methyl- $N^{\prime}$-nitro- $N$-nitrosoguanidine (MNNG) (Aldrich Chemical Co. Inc., Milwaukee, Wisconsin, U.S.A.) was dissolved $0.1 \%(\mathrm{w} / \mathrm{v})$ in sterile 
water. Deoxyribonuclease (DNAse) (British Drug Houses) was dissolved 0.I \% (w/v) in sterile physiological saline.

Preparation of DNA. Bacteria were harvested in the late exponential phase from $450 \mathrm{ml}$. aerated cultures grown in TYE medium supplemented adequately for haemin auxotrophs contained in 21 . flasks and DNA extracted according to the method of Marmur (196I). Both purified DNA and deproteinized crude extracts were used in transformation studies. The concentration of DNA was estimated in purified preparations by measuring optical density at $260 \mathrm{~m} \mu$ and in crude extracts chemically according to the method of Burton (1956).

Transformation. The method recommended by Anagnostopoulos \& Spizizen (196I) was employed after suitable modification-see text.

Cytochrome estimation. Absorption spectra of bacterial suspensions were measured in the reduced state at temperatures of liquid nitrogen $\left(-190^{\circ}\right)$ in a Cary 15 recording spectrophotometer.

\section{RESULTS}

\section{Isolation of haemin auxotrophs}

Selection by streptomycin after irradiation with u.v. light. Samples were taken from a culture of RI 2 during the exponential phase of growth in MD broth, centrifuged, resuspended in buffered saline and irradiated with u.v. Fluorescence Lamp (Hanovia, Slough, Bucks., England). The suspension was then diluted I/Io (v/v) with MD broth and re-incubated for $2 \mathrm{hr}$ before $0.1 \mathrm{ml}$. samples were plated on MD agar containing $200 \mu \mathrm{g}$. streptomycin sulphate $/ \mathrm{ml}$.; pre- and post-irradiation dilutions were plated on MD agar to determine the survival rate. At $5 \%$ survival the colonies after $48 \mathrm{hr}$ incubation on the streptomycin plates were of two types; $(a)$ creamy colonies more than $3 \mathrm{~mm}$. in diam. and $(b)$ round, transparent colonies less than $0.5 \mathrm{~mm}$. in diam. Strain RI 4 was taken from a colony of the first type; it was resistant to $500 \mu \mathrm{g}$. streptoymcin/ml. but was auxotrophic for tryptophan alone. Strain RI 5 was taken from a colony of the second type which showed an increase in size only on subculture to media containing blood; it was resistant to $50 \mu \mathrm{g}$. streptomycin $/ \mathrm{ml}$. Although a similar increase in colony size was observed on MD agar supplemented with $2.5 \mu \mathrm{g}$. haemin/ml., identity as a haemin auxotroph was not established until a minimal medium had been defined. In two further experiments, in which the survival rate was less than I $\%$, small colony formers were encountered but none showed enhanced growth on haemin supplemented MD agar.

Exposure to copper ions. Mutants of Bacillus subtilis have been isolated by Weed (1963) after exposure of organisms to copper sulphate. We modified his method to include $2.5 \mu \mathrm{g}$. haemin $/ \mathrm{ml}$. in the copper medium and inoculated $\mathrm{Io} \mathrm{ml}$. medium in $100 \mathrm{ml}$. screw-capped bottles with $\mathrm{I} \mathrm{ml}$. of an exponentially growing culture of strain RI 4 in MD broth, containing $1 \times 10^{8}$ colony formers per ml. Bottles were incubated at either $37^{\circ}$ or $43^{\circ}$. At intervals from the second to the seventh day loopfuls of suspension were plated out on MD agar containing I $\mu \mathrm{g}$. haemin $/ \mathrm{ml}$. Inspection with a hand lens in the region of individual colonies after 48 to $72 \mathrm{hr}$ incubation revealed a low proportion of transparent colonies, $\mathrm{O} \cdot \mathrm{I}-\mathrm{I} \mathrm{mm}$. in diam., amongst the creamy, $5 \mathrm{~mm}$. diam. colonies of the parent strain; these transparent colonies were subcultured on to MD agar, both plain and supplemented with $2.5 \mu \mathrm{g}$. haemin/ml. Five strains, which showed improved growth on haemin media, were later confirmed as haemin auxotrophs 
and labelled RI 6 (from $37^{\circ}$ incubation), RI 7, RI 8, RI 9 and RI IO (from $43^{\circ}$ incubation).

Exposure to $N$-methyl- $N^{\prime}$-nitro- $N$-nitrosoguanidine. The technique independently described by Davis (1948) and Lederberg \& Zinder (1948), in which penicillin was used to enrich the yield of auxotrophs, has since been adapted successfully by many workers. The fact that a minimal medium was defined (see below) in which haemin auxotrophs grew well permitted the use of the following modification to isolate one further strain, RI II. Bacteria of strain RI 4, growing exponentially in MD broth, were washed with buffered saline at $\mathrm{pH} 7$ and resuspended in the same volume of buffered saline containing $50 \mu \mathrm{g}$. MNNG $/ \mathrm{ml}$. Exposure for $30 \mathrm{~min}$. at $37^{\circ}$ was terminated by immersion in melting ice before the tubes were centrifuged. The washed sediment was resuspended in Io $\mathrm{ml}$. MD broth containing $5 \mu \mathrm{g}$. haemin $/ \mathrm{ml}$. plus $500 \mu \mathrm{g}$. AFV $/ \mathrm{ml}$. and incubated overnight. Samples of $2 \mathrm{ml}$. each were added to $50 \mathrm{ml}$. GGM in $250 \mathrm{ml}$. flasks containing $200 \mu \mathrm{g} . / \mathrm{ml}$. vitamin-free casamino acids (Difco Labs, Detroit, Michigan, U.S.A.) and incubated for $4 \mathrm{hr}$ in the shaker before Methicillin to a final concentration of $1000 \mu \mathrm{g} . / \mathrm{ml}$. was added. After further overnight incubation, $0 \cdot \mathrm{I} \mathrm{ml}$. samples from a suspension in GGM of repeatedly washed bacteria were spread on GGM suitably supplemented for haemin auxotrophs. I60 colonies were replica plated but only one strain, RI I I, was haemin dependent.

\section{Cultural characteristics of haemin auxotrophs}

The results of growth on MD supplemented with haemin were inconsistent and always poorer than those obtained on BM. The absence of colony formation on minimal medium supplemented with haemin alone or in combination with casamino acids, vitamins or nucleic acid bases indicated the importance of other factors in the promotion of growth. It was observed that the presence of non-specific substances, e.g. charcoal or DEAE cellulose, in a minimal medium containing casamino acids and haemin permitted a limited degree of colony formation; when AFV was used instead of charcoal the growth was further improved. Finally it was found that for routine cultures of haemin auxotrophs of Bacillus subtilis (directly or indirectly derived from RI 2) a minimal medium supplemented with tryptophan $(50 \mu \mathrm{g} . / \mathrm{ml}$.), cysteine or cystine (10-25 $\mu \mathrm{g} . / \mathrm{ml}$.), AFV (500 $\mu \mathrm{g} . / \mathrm{ml}$ ) ) and haemin $(5 \mu \mathrm{g} . / \mathrm{ml}$.) promoted colony formation, after $48 \mathrm{hr}$ incubation, almost equivalent to that obtained on BM after $24 \mathrm{hr}$. The requirements in fluid media were identical. Neither methionine nor thioglycollic acid was capable of replacing cysteine or cystine in the minimal medium.

The mutants (RI 5 to RI II) were maintained by weekly transfer on to fresh BM and were stored in the refrigerator at $4^{\circ}$ after initial incubation for $24 \mathrm{hr}$. The requirement for haemin was not seen to be diminished or lost in any strain; spontaneous reversion to haemin independence occurred at a frequency less than $10^{-7}$. Cellular morphology and reaction to Gram stain did not suffer from those of the parent and the biochemical markers, tryptophan dependence and streptomycin resistance, were present. Sensitivity to a set of Bacillus subtilis phages was identical in parent and mutant strains. The ability of the mutants to sporulate was impaired. The colony formed by haemin auxotrophs on supplemented minimal medium after $48 \mathrm{hr}$ incubation was small, 2-3 mm. in diam., moist and more regular in comparison to the $5 \mathrm{~mm}$. diam., dry, irregular colony of strain RI 2, from which they were all derived; this difference was not further examined. Neither parent nor mutant strains could be cultured anaerobically. 


\section{Porphyrin utilization and synthesis by auxotrophs}

The range of haemin concentrations necessary to support growth showed an upper and a lower limit. Whilst $2 \cdot 5-5 \mu \mathrm{g}$. $/ \mathrm{ml}$. promoted adequate colony formation on solid, defined media, concentrations between I and $2 \mu \mathrm{g}$. haemin $/ \mathrm{ml}$. were satisfactory in fluid media, although a uniform bacterial density was not reached in every experiment. Quantities in excess of $5 \mu \mathrm{g} . / \mathrm{ml}$. proved inhibitory to growth in both solid and fluid media.

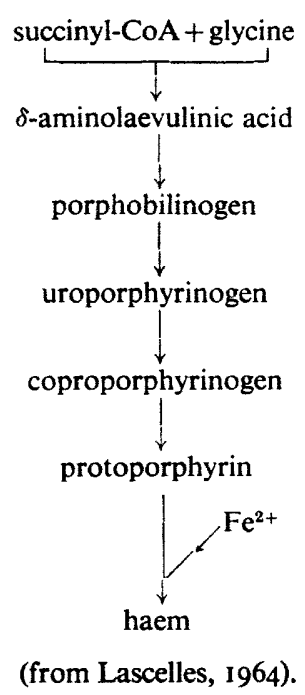

Fig. I. Pathway of porphyrin synthesis.

None of the mutants grew when haemin was substituted by protoporphyrin IX or the porphyrin containing compounds, cytochrome $c$ and catalase. Coproporphyrin, uroporphyrin and porphobilinogen were not tested for their ability to replace haemin. However, two isolates, RI 5 and RI 6, were capable of utilizing $\delta$-aminolaevulinic acid, the first specific intermediate in the pathway to porphyrin synthesis (see Fig. I), and grew well in minimal medium supplemented only with tryptophan and $2.5 \mu \mathrm{g}$. ALA/ ml.; no growth was obtained when ALA was replaced by pyridoxal phosphate. The growth response of RI 5 to ALA in minimal medium is illustrated in Fig. 2.

While catalase itself did not satisfy the porphyrin requirements of the mutants it allowed a considerable reduction in the quantity of haemin required for optimal growth of the bacteria. This 'sparing' effect was observed in solid and fiuid media; with $40 \mathrm{e} . \mathrm{u} . / \mathrm{ml}$. catalase a concentration of $0 . \mathrm{I} \mu \mathrm{g}$. haemin $/ \mathrm{ml}$. was sufficient for optimal growth.

The cytochrome absorption spectrum of three mutants, RI 5, RI 6 and RI 7, was not found to vary significantly from RI 2, whether the organisms were grown in non-defined medium or supplemented minimal medium. Absorption maxima representing bands of cytochrome $a+a_{3}(598-602 \mathrm{~m} \mu)$ and cytochrome $c_{1}(553-555 \mathrm{~m} \mu)$, with their $\beta$ $(525-527 \mathrm{~m} \mu)$ and $\gamma$ or Soret bands (440 and $420 \mathrm{~m} \mu$ ), were identified in all samples using references taken from Smith (1954) and Sherman (1963). 


\section{Transformation efficiency of mutants}

The haemin auxotrophs required longer incubation times than RI 2 to reach comparable cell densities in supplemented minimal medium. Tomasz (1966) and Thorne \& Stull (I966) have stressed the importance of transferring bacteria at an optimum cell density from the first growth medium (GM) into fresh transformation medium (TM) to obtain a high yield of transformants. Bacteria were grown to a cell density of $5 \times 10^{8}$ colony formers $/ \mathrm{ml}$. in GM, then centrifuged, resuspended in Io vol. TM and incubated in the shaker for $90 \mathrm{~min}$. before DNA was added to a final concentration of $10 \mu \mathrm{g} . / \mathrm{ml}$.

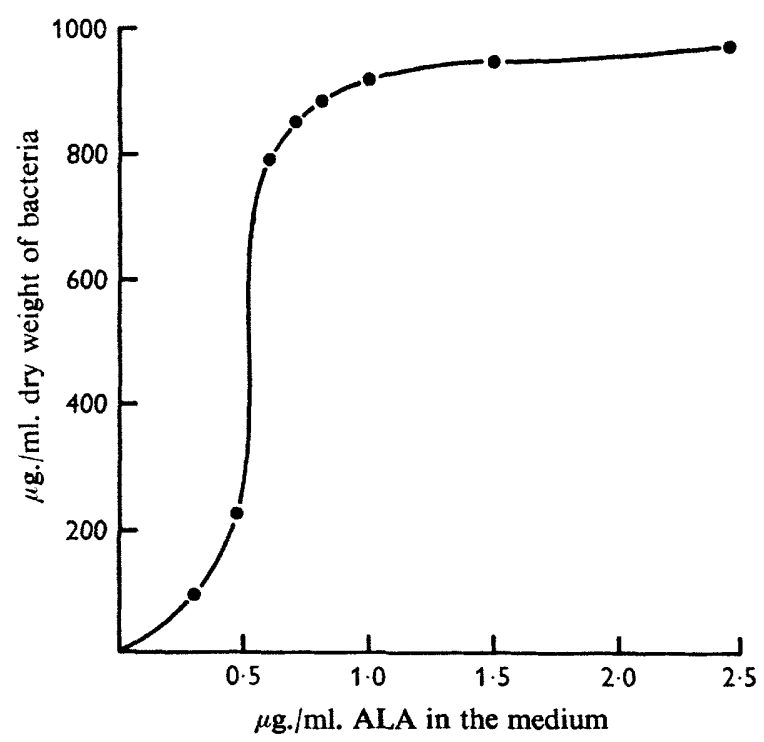

Fig. 2. Growth responses of strain RI 5 to $\delta$-aminolaevulinic acid. $10 \mathrm{ml}$. supplemented minimal medium in $100 \mathrm{ml}$. flasks were inoculated with $5 \times 10^{4}$ washed colony formers from an overnight culture of the strain in supplemented minimal medium containing $2.5 \mu \mathrm{g}$. ALA/ml. The optical density value after $20 \mathrm{hr}$ incubation was converted to dry weight of bacteria per $\mathrm{ml}$. The bacterial yield is plotted as a function of the concentration of ALA.

Exposure for $30 \mathrm{~min}$. was terminated by the addition of DNAse to a final concentration of $100 \mu \mathrm{g} . / \mathrm{ml}$. and incubation was continued for $15 \mathrm{~min}$. before $0.1 \mathrm{ml}$. samples of dilutions in minimal medium were spread on appropriately supplemented minimal agar. Colony counts were made after $48 \mathrm{hr}$ incubation. The results of transformation experiments are summarized in Table 2.

Transformation occurred with acceptable efficiency in the strains RI 5 and RI 6 when the experiments were performed in media supplemented with ALA. The yield of transformants was one log. unit less in haemin-supplemented minimal media even with reduced concentrations of haemin in the presence of catalase. When RI 5 was used as recipient with diminishing concentrations of prototrophic (RI I) DNA a marked reduction in transformants occurred at concentrations below $0.1 \mu \mathrm{g} . / \mathrm{ml}$., although transformants were still recovered at a concentration of $0.005 \mu \mathrm{g} . / \mathrm{ml}$.

A low rate of transformation was found in RI 7 and RI 8 both of which could only be grown in media supplemented with haemin. When DNA from RI 7 (carrying 
hem-3) was used to transform RI 3 to histidine independence the resulting colony formers were replica plated on to supplemented minimal medium with and without haemin to give a rate for double transformants (genotype trp, hem-3) of $4 \times 10^{2}$ per $10^{8}$ recipients. The haemin solution used was freshly made and did not contain histidine. One of these double transformants, RI I2, was transformed to haemin independence in haemin media at a higher rate than $\mathrm{RI} 7$ (see Table 2) under identical conditions, although both strains carried the same defective allele (hem-3) for haem synthesis.

Table 2. Transformation of Bacillus subtilis strains

\begin{tabular}{|c|c|c|c|c|c|c|}
\hline \multirow{2}{*}{$\begin{array}{l}\text { Reci- } \\
\text { pient } \\
\text { strain }\end{array}$} & \multirow{2}{*}{$\begin{array}{l}\text { Donor } \\
\text { strain } \\
\text { (DNA } \\
\text { conc. } \\
\text { Io } \mu \mathrm{g} . / \\
\text { ml.) }\end{array}$} & \multicolumn{5}{|c|}{ Transformation to independence in $10^{8}$ recipients } \\
\hline & & Trp & Hem & Trp + Hem & His & Trp + His \\
\hline Ri 2 & RI I & $1.5 \times 10^{5}$ & . & . & . & . \\
\hline$R \times 4$ & RI I & $1.0 \times 10^{5}$ & . & . & . & . \\
\hline RI $5^{*}$ & RI I & $1.4 \times 10^{5}$ & $1 \cdot 3 \times 10^{5}$ & $4.0 \times 10^{3}$ & . & . \\
\hline RI $5^{*}$ & RI 6* & $<$ IO & $<10$ & $<$ IO & . & . \\
\hline RI $5^{*}$ & RI 9 & $<10$ & $1 \cdot 0 \times 10^{5}$ & $<10$ & . & . \\
\hline RI $6^{*}$ & RI I & . & $1.0 \times 10^{4}$ & . & . & . \\
\hline RI 7 & RI I & . & $5.0 \times 10^{2}$ & . & . & . \\
\hline RI 8 & RI I & . & $1.5 \times 10^{2}$ & . & . & . \\
\hline RI 3 & RI I & $3.0 \times 10^{4}$ & . & . & $2.4 \times 10^{4}$ & $2.4 \times 10^{4}$ \\
\hline R1 3 & RI 7 & . & . & . & $1.0 \times 10^{4}$ & . \\
\hline RI 12 & RI I & $1.2 \times 10^{5}$ & $0.8 \times 10^{5}$ & $3.0 \times 10^{3}$ & . & . \\
\hline
\end{tabular}

Trp $=$ tryptophan, Hem $=$ haemin, His $=$ histidine, $(*)=$ utilizes ALA

Transformation experiments were performed as described in the text. Samples of o. $1 \mathrm{ml}$. from appropriate dilutions were plated on suitably supplemented minimal medium. Averages of colony counts on three plates after $48 \mathrm{hr}$ incubation are expressed as transformants per $10^{8}$ recipients.

\section{DISCUSSION}

A streptomycin resistant mutant of Staphylococcus aureus was reported to show a requirement for haemin by Jensen \& Thofern (I953). Beljanski \& Beljanski (I957) isolated a similar mutant from Escherichia coli by a process of selection using streptomycin. The isolation of a haemin auxotroph of Bacillus subtilis on a medium containing streptomycin provided a further example of the intriguing relationship between these two characters.

A greater number of haemin dependent mutants was obtained when colonies were selected on the basis of diminished colony size after growth in copper-containing medium. In these experiments a small quantity of haemin was added to the selection medium in order to supplement the variable, intrinsic concentration of porphyrins in MD. The 'small colony' strain, SC 22, isolated by Weed (1963) after exposure to copper, was studied in this laboratory due to the kindness of Dr Weed. His strain was not found to have an improved growth on media supplemented with haemin and was refractory to a group of subtilis phages to which RI 2 and haemin auxotrophs were sensitive.

Jensen \& Thofern (1953) and Beljanksi \& Beljanski (1957) used a peptone-glucose medium supplemented with haemin to cultivate their mutants under conditions of diminished oxygen concentration and were unable to define a 'synthetic' medium. 
The haemin auxotrophs of Bacillus subtilis attained full aerobic growth in a chemically defined minimal medium(GGM or Spizizen) supplemented with cysteine or cystine and AFV in addition to haemin. Under these conditions a normal cytochrome electron transport mechanism was formed as judged by the cytochrome absorption spectrum. The minimal concentration of haemin $(0 \cdot 1 \mu \mathrm{g} . / \mathrm{ml}$.) to which the response of the strains was optimal compared favourably with the minimal porphyrin requirement of Haemophilus influenzae strains (Granick \& Gilder, 1946) and confirmed the specific nature of the dependence.

That the strains utilizing ALA were capable of optimal growth in media supplemented with ALA alone suggested that AFV and cysteine or cystine were important only in haemin media. Pollock (1947) demonstrated the ability of charcoal, albumin and starch to neutralize the inhibitory effects of unsaturated fatty acids in the medium. Davis \& Dubos (1947) found bovine albumin, fraction V, to be most effective in promoting growth in the presence of inhibitors (e.g. unsaturated fatty acids) and attributed this property to the capacity of the molecule to bind, and slowly release, compounds inhibitory to growth at higher concentrations. We did not characterize the substances inhibiting the growth of haemin auxotrophs. The supportive effect given by charcoal, albumin, or cellulose, of a cationic character, to growth of the haemin auxotrophs in the presence of haemin indicated the acid properties of the inhibitors. Haemin was growth-limiting above certain concentrations; it was also possible that AFV, by virtue of its capacity to bind and release compounds, maintained the haemin concentration at growth-promoting levels.

Cysteine or cystine was indispensable for growth in haemin minimal medium already containing substances able to neutralize fatty acids and peroxides. The mechanism necessitating the inclusion, specifically, of either of these amino acids was not determined. The activity of catalase in sparing haemin was explained by the known destructive effect of $\mathrm{H}_{2} \mathrm{O}_{2}$ on haem compounds (Gilder \& Granick, 1947).

The inability of the strain of Jensen \& Thofern (1953) to utilize protoporphyrin was attributed to a deficiency of the enzyme 'ferrochelatase', which catalyses the insertion of iron into protoporphyrin. Lack of this enzyme did not account for the failure of strains RI 5 and RI 6 to grow in media supplemented with protoporphyrin since growth and synthesis of porphyrins by these strains in minimal media supplemented with ALA indicated the possession of all enzymes except ALA synthetase. It is possible that protoporphyrin did not penetrate into these organisms. It is also possible that, in Bacillus subtilis species, iron is inserted into the porphyrin ring at an earlier stage.

The transformation experiments were only preliminary. Their purpose was to demonstrate how a detailed study of a larger number of similar mutants could contribute to an understanding of the genetic control of iron-porphyrin synthesis in Bacillus subtilis. The high percentage of wild-type transformants recovered from RI 3 exposed to prototrophic (RI I) DNA confirmed the proximity of the defective loci for histidine and tryptophan synthesis in that strain (Nester, Schafer \& Lederberg, 1963). By comparison the low recovery of double transformants from RI 5 even with saturating levels of prototrophic (RI I) DNA was interpreted to mean that the haem and tryptophan loci were distant from each other. An intrinsic, low level of competence, i.e. ability to accept exogenous DNA, was thought to be the reason for the poor efficiency of transformation in some strains.

In the nomenclature of bacterial genetics it has been recommended (Demerec, 
Adelberg, Clark \& Hartman, 1966) that a capital letter should follow the abbreviation of the mutated metabolic pathway in order to indicate which enzyme step is involved, where this is known. We propose, therefore, that hemA should be used to denote that region of the chromosome of Bacillus subtilis which determines ALA synthetase activity since the reaction catalysed by this enzyme is well established (Lascelles, 1964) as the initial step on porphyrin synthesis. Strain RI 5 then carries hemAI and RI 6 carries hemA2; it is hoped that subsequent work will establish where the block is in the porphyrin metabolic pathway of the other mutants.

The authors wish to thank Professor P. P. Slonimski and Dr C. Anagnostopoulos, Laboratoire de Génétique et Physiologique, Gif-sur-Yvette, for the estimation of cytochrome spectra, Dr L. Weed for the sample of his strain and Dr J. McGeachie for criticism of the original manuscript. The valuable technical assistance of $\mathrm{Mr}$ J. Forrester is gratefully acknowledged. The work was aided by a grant from the Scottish Hospital Endowments Research Fund and was carried out during the tenure of the McFarlane Chair of Experimental Medicine by one of us (G. I.); the other author is privileged to hold the post of McGhie Cancer Research Scholar.

\section{REFERENCES}

Anagnostopoulos, C. \& Spizizen, J. (1961). Requirements for transformation in Bacillus subtilis. J. Bact. 81, 741.

Beljanski, M. \& Beljanski, M. (1957). M. Sur la formation d'enzymes respiratoires chez un mutant d'Escherichia coli streptomycine-résistant et auxotrophe pour l'hémine. Annls Inst. Pasteur, Paris 92, 396.

Burton, K. (1956). A study of the conditions and mechanisms of the diphenylamine reaction for the colorimetric estimation of deoxyribonucleic acid. Biochem. J. 62, 315.

Csiszár, K. \& Ivánovics, G. (1965). Transduction in Bacillus subtilis. Acta microbiol. hung. 12, 73.

Davis, B. D. (1948). Isolation of biochemically deficient mutants of bacteria by penicillin. J. Am. chem. Soc. 70, 4267 .

Davis, B. D. \& Dubos, R. J. (I947). The binding of fatty acids by serum albumin, a protective growth factor in bacteriological media. J. exp. Med. 86, 215.

Demerec, M., Adelberg, E. A, Clark, A. J. \& Hartman, P. E. (1966). A proposal for a uniform nomenclature in bacterial genetics. Genetics $54,6 \mathrm{I}$.

FöLDEs, J. \& MOLNÁR, J. (1964). Isolation and characteristics of some Bacillus subtilis phages with 'transforming' activity. Acta microbiol. hung. II, 165.

Grlder, H. \& Granick, S. (1947). Studies in the Haemophilus group of organisms. J. gen. Physiol. $3 \mathbf{1}, 103$.

Granick, S. \& GiLder, H. (1946). The porphyrin requirements of Haemophilus influenzae and some functions of the vinyl and propionic acid side chains of heme. J. gen. Physiol. 3o, I.

JENSEN, V. J. \& THOFERN, E. (1953). Chlorhämin (ferriporphyrinchlorid) als Bakterienwuchstoff I. Z. Naturf. 8 b, 599 .

LASCELles, J. (1964). Tetrapyrrole Biosynthesis and its Regulation. New York: W. A. Benjamin, Inc.

LEDERBERG, J. \& ZINDER, N. (I948). Concentration of biochemical mutants of bacteria with penicillin. J. Am. chem. Soc. $70,4267$.

MARMUR, J. (196I). A procedure for the isolation of deoxyribonucleic acid from micro-organisms. J. molec. Biol. 3, 208.

Nester, E. W., Schafer, M. \& Lederberg, J. (1963). Gene linkage in DNA transfer: a cluster of genes concerned with aromatic biosynthesis in Bacillus subtilis. Genetics 48, 529 .

Pollock, M. R. (1947). Haemophilus pertussis in media without blood. Br. J. exp. Path. 28, 295.

Sherman, F. (1963). The genetic control of the cytochrome system in yeast. Colloques int. Cent. natn. Rech. scient. 124, I.

SMrrH, L. (1954). Bacterial cytochromes. Bact. Rev. 18, 106. 
SPENCER, H. J. \& HerRIOT, R. M. (1965). Development of competence in Haemophilus influenzae. J. Bact. 90, 9 II.

SPIZIZEN, J. (1958). Transformation of biochemically-deficient strains of Bacillus subtilis by deoxyribonucleate. Proc. natn. Acad. Sci. U.S.A. 44, 1072.

THORNe, C. B. \& Stull, H. B. (1966). Factors affecting transformation of Bacillus licheniformis. J. Bact. 91, IOI 2.

Tomasz, A. (1966). Model for the mechanism controlling the expression of competent state in penumococcus cultures. J. Bact. 9r, 1050.

WeED, L. (1963). Effects of copper on Bacillus subtilis. J. Bact. 85, 1003. 